Journal of Business Management and
Economic Research

\title{
The Economic and Statistical Evaluation of Climatic Elements in Tabriz and Isfahan (in Iran)
}

\section{Mohammad Yazdani}

Ph.D. student of Climatology, Tabriz University, Tabriz, Iran

Department of Climatology, Faculty of Planning and Environmental Sciences, Tabriz University, Tabriz, Iran

yazdani@tabrizu.ac.ir

\begin{abstract}
Climatic Elements involve potential values and play main role in this regard that is not truly known and acknowledged by the public. Among climatic factors, elements such as temperature, precipitation and freezing have most affected the formation and the growth of human societies. these elements can influence the agricultural production, thereby affecting the economic activities of humans in various scales. Currently, in developed countries they apply different statistical agroclimate models involving predictions and pricing methods and also the estimation of insurance value of climatic elements in order to manage the possible agricultural crises. In this study, with the aim of evaluating the economic value of climate, different climatic factors such as temperature, precipitation, and freezing have been estimated. Four products of namely, arable wheat, dry farm wheat, arable barley and dry farm barley have been chosen for Tabriz and Isfahan's agricultural fields. The production amounts have given rise to the estimation of per hectare net income, which in turn is a function of climatic factors. Various statistical techniques including correlation, multiple and stepwise regression models have been applied.
\end{abstract}

Keywords: Economic Climatology, Statistical Models, Economic Valuation and Agricultural, Climatic Elements 


\section{Introduction}

Climatic elements have always been effective in human activities and during the course of history have led to the emergence of various geographic theories such as determinism and, as a result, the prosperity of geographical philosophical debates. Among different climatic elements, temperature, precipitation and freezing have had a great influence on the formation and growth of human societies. These elements can influence the amount of crop production and control economic activities of humans at different scales. Thus, the estimation of the economic value of climatic elements in the agricultural economy can become a major objective. As a result, in this research, the problem is the determination and estimation of the economic value of climate elements affecting agriculture in two different latitudinal areas and, consequently, having different characteristics of agricultural products. Using different methods, researchers have been involved in the economic estimation of climatic elements affecting agriculture. Mendelsohn et al. (1999) have used the Ricardian approach to study the relationship between climate diversity and the value of agricultural land. They apply this method to products in different areas and have tried to provide a clear indication of the use of experience from data from hot areas on cooler areas. The main advantage of this method is that, when evaluating the relationship between agricultural operations and climate characteristics, the compatibility of these two at the farm level is considered (Mendelsohn et al., 1999, p. 281). This method has also been used in Brazil and India by Sanghe (1997), Kumar \& Parikh (1998) and Mendelsohn and Dinar (1999) to estimate the effects of climate on crops.

Kumar \& Parikh (2001) estimated the practical relationship between net income of the farm and climate variables, taking into account soil diversity, geographic and economic changes using the cross- section (district level) and statistical time series. To understand the sensitivity of data and climate elements to Indian agriculture, they have predicted using linear methods, equations and their mutual performance that there is a practical relationship between net income at farm level and climate variables and Using a model and analysis of data at each level in the area during the period from 1970 to 1980, they evaluated the performance of adapted weather in a long-term period (Kumar \& Parikh 2001: 148). In a related but different study, Brown et al. (2002) analyzed the forecasted results of a sample for Return of climatological information and economic values of predictions for the two Havre and Williston regions. (Brown et al. 2002: 840). then They describe a dynamic model of dynamic decision making that can determine the type of extensive plain cultivation in the northern 
region or the possibility of sowing them. They predict the existence of seasonal precipitation in most cases with significant economic value and, on the other hand, consider the relationship between prediction quality and its value to rainfall in effective economic appraisals. Katz and Murphy (2001) have presented a model for determining the value of weather forecasting in orchards to describe the relationships between decisions and events in different situations, in which the valuation of data shows that the main goal of gardeners, Reduce the costs incurred during a frosty season. (Katz \& Murphy 2001: 528). This model is a macro decision making process, along with a dynamic programming method that is used to determine the best gardener's performance during a season, and to identify the expected costs of these. They have used this model in Yakima valley in central Washington to determine the value of weather information and predict the analysis of the decision making process. The analysis of the decision making process creates a very suitable and special template, whereby the value of climate data is studied. A study that studies the relationship between the accuracy and value of these minimum temperature (frost) predictions shows that this relationship is non-linear.

\section{Geographical Situation and Topography of Tabriz}

Tabriz is the center of East Azarbaijan province with an altitude of 1361 meters above sea level and with an area of 356.2 square kilometers between 38 degrees 1 minute to 9 minutes longitude and 46 degrees and 11 minutes to 23 minutes of the eastern length. The topography consists of three parts: the northern heights, southern heights (Sahand Shafts) and the smooth section of Tabriz plain. This area is in fact part of the Tabriz Alluvial Deposit, spreading from the West to the Urmia Sea. The most important river in this area is Aji Chay.

\section{Geographical Situation and Topography of Isfahan}

The city of Isfahan is the largest living complex in the central plateau of Iran. It is located in a vast plain between the eastern slopes of Zagros and the central mountain range, located at 32 degrees and 38 minutes in the northern latitude and 51 degrees and 39 minutes in the eastern plain. The height of this city is 1590 meters above sea level and its minimum air gap is 300 kilometers to the free surface of the Persian Gulf. The permanent flow of water from the central region of Iran, Zayandehrood, passes through the city. 


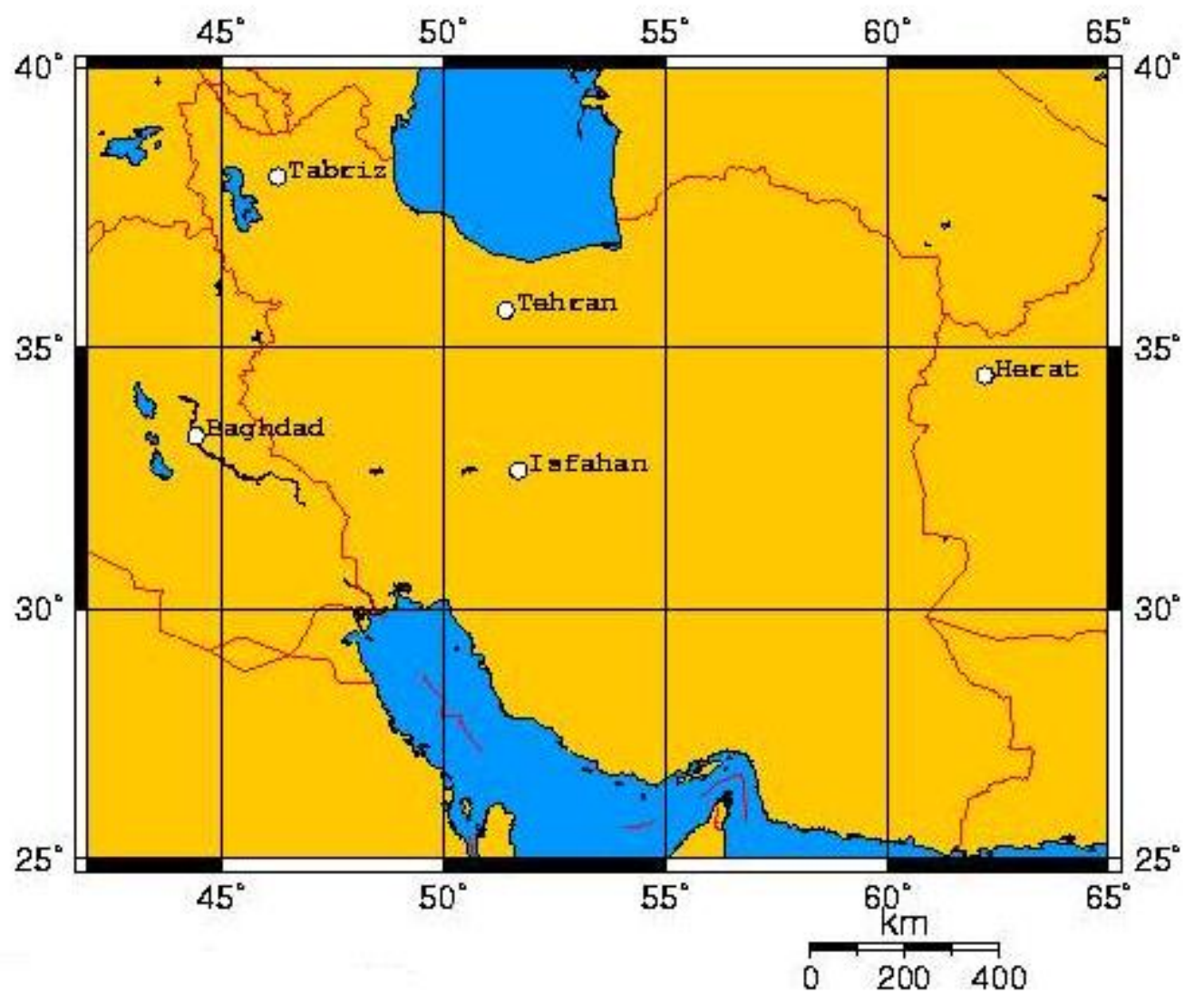

Figure 1. Geographical situation of Tabriz and Isfahan cities

\section{Methods and materials}

At first, two different climate zones were considered for study: Isfahan as a city or region located in the inner mountainous region with dry and warm climate and Tabriz located in the mountainous region in the semi-arid climate and cool. According to the study of elements and climatic factors of temperature, precipitation and freezing and their economic evaluation in this article, a detailed comparison of the elements and factors mentioned in the studied areas are discussed. The structure of the classification and entry of data into the statistical package of the "Minitab " has been as follows: Firstly, the mean of all data (including independent variables and dependent variables in ordered years) has been calculated from 1985 to 2015 and the calculated number is considered as the mean annual of the same variable. For example, in relation to Tabriz's 30-year data, the average annual temperature in 1985 was calculated as 12.62 degrees centigrade. This trend has been calculated for all data from Isfahan and Tabriz. 


\subsection{Precipitation}

For the formation of precipitation, the presence of wet air and climb factor are required. In the studied areas, the lakes and rivers are not enough to provide the necessary moisture for precipitation in their adjacent areas. These resources are more local and affect the relative humidity of the air. Thus, the Tabriz area is somewhat influenced by the humidity of the Urmia Sea and the Caspian Sea. Of course, the role of Lake Urmia is dimmed due to its drying. and the Isfahan area is less relative humidity than Tabriz due to its lack of close proximity to an important lake. In any case, the moisture content required for precipitation in the studied regions is based on the water resources of the Mediterranean Sea under the western winds of the cold season, which provides instability for the ascension of the air.

Table 1. Temperature and precipitation properties of Tabriz and Isfahan cities during the study period (1985-2015)

\begin{tabular}{|c|c|c|c|c|c|c|c|c|}
\hline $\begin{array}{c}\text { City } \\
\text { Name }\end{array}$ & $\begin{array}{c}\text { Height } \\
(\mathrm{m})\end{array}$ & $\begin{array}{c}\text { Mean January } \\
\text { temperature } \\
\left({ }^{\circ} \mathrm{C}\right)\end{array}$ & $\begin{array}{c}\text { Mean July } \\
\text { temperature } \\
\left({ }^{\circ} \mathrm{C}\right)\end{array}$ & $\begin{array}{c}\text { Maximum } \\
\text { temperature of } \\
\text { year }\left({ }^{\circ} \mathrm{C}\right)\end{array}$ & $\begin{array}{c}\text { Minimum } \\
\text { temperature of } \\
\text { year }\left({ }^{\circ} \mathrm{C}\right)\end{array}$ & $\begin{array}{c}\text { The mean } \\
\text { annual } \\
\text { frozen days }\end{array}$ & $\begin{array}{c}\text { mean annual } \\
\text { temperature } \\
\left({ }^{\circ} \mathrm{C}\right)\end{array}$ & $\begin{array}{c}\text { Annual } \\
\text { precipitatio } \\
(\mathrm{mm})\end{array}$ \\
\hline Tabriz & 1361 & -1.66 & 26.05 & 28.7 & -8.4 & 92.66 & 12.48 & 245.24 \\
\hline Isfahan & 1590 & 3.54 & 30 & 38.3 & -1 & 68.71 & 16.68 & 111.5 \\
\hline
\end{tabular}

\subsection{Temperature}

The specifications of the temperature of Tabriz and Isfahan cities are given in Table 1. According to this table, the difference in temperature between these two regions is less than $3^{\circ} \mathrm{C}$, while in winter this difference exceeds $5.5^{\circ} \mathrm{C}$.

Table 2. Monthly mean of climatic elements in Tabriz and Isfahan cities during the study period (1985-

2015)

\begin{tabular}{|c|c|c|c|c|c|c|}
\hline \multicolumn{3}{|c|}{ Tabriz } & City Name & \multicolumn{3}{|c|}{ Isfahan } \\
\hline \multirow[t]{2}{*}{$\begin{array}{c}\text { Temperature } \\
\left({ }^{\circ} \mathrm{C}\right)\end{array}$} & \multirow[t]{2}{*}{$\begin{array}{l}\text { Precipitation } \\
\quad(\mathrm{mm})\end{array}$} & \multirow[t]{2}{*}{$\begin{array}{c}\text { Frozen } \\
\text { (day) }\end{array}$} & $\begin{array}{l}\text { Climatic } \\
\text { element }\end{array}$ & \multirow[t]{2}{*}{$\begin{array}{c}\text { Temperature } \\
\left({ }^{\circ} \mathrm{C}\right)\end{array}$} & \multirow[t]{2}{*}{$\begin{array}{l}\text { Precipitation } \\
\quad(\mathrm{mm})\end{array}$} & \multirow[t]{2}{*}{$\begin{array}{c}\text { Frozen } \\
\text { (day) }\end{array}$} \\
\hline & & & Month & & & \\
\hline-1.66 & 17.38 & 28.06 & Jan & 3.54 & 15.5 & 25.46 \\
\hline-0.6 & 15.12 & 23.39 & Feb & 6.16 & 14.34 & 16.73 \\
\hline 5.12 & 33.44 & 13.19 & Mar & 10 & 29.3 & 4.86 \\
\hline 11.87 & 40.12 & 10.26 & Apr & 16.68 & 9.9 & 0 \\
\hline 17.07 & 35.62 & 0 & May & 21.96 & 6.6 & 0 \\
\hline 22.74 & 11.37 & 0 & Jun & 25.16 & 2.38 & 0 \\
\hline 26.05 & 6.44 & 0 & Jul & 30 & 1.22 & 0 \\
\hline
\end{tabular}




\begin{tabular}{|c|c|c|c|c|c|c|}
\hline 25.74 & 4.20 & 0 & Aug & 27.92 & 0.34 & 0 \\
\hline 21.03 & 4.96 & 0 & Sep & 23.82 & 0 & 0 \\
\hline 13.98 & 24.33 & 0 & Oct & 16.1 & 4.7 & 0 \\
\hline 6.69 & 24.1 & 7.53 & Nov & 17.82 & 12.12 & 3.46 \\
\hline 1.3 & 28.46 & 19.46 & Dec & 5.53 & 15.1 & 18.2 \\
\hline 12.48 & 245.24 & 92.66 & annual & 16.68 & 111.5 & 68.71 \\
\hline
\end{tabular}

\subsection{Frozen}

A frozen day is said to be every 24 hours during which the minimum air temperature reaches zero or less than zero degrees. Considering the mountainousness of Tabriz and the possibility of very cold air transfer to low-altitude plains and with the possibility of a very cold air mass in the Azerbaijan area, it seems that most of the cold-weather days of the region are related to the arrival of cold air masses. Table2 indicates that the maen frozen point in Tabriz during the statistical period reaches 66.69 days per year. The maximum frozen point in this city is January with an maen of 28.06 days and $30.28 \%$ of the total annual frost, while April with the maen of 1.26 and $1.35 \%$, the lowest frost was allocated. Radiant freezes, which are usually formed in smooth and calm nights, may seem to prolong the period of spring frost in Tabriz. In general, it should be acknowledged that the occurrence of frost in Tabriz begins in November and ends in April, which also causes a shortened plant growth period. In Isfahan, the mean annual frozen during the statistical period reaches 68.7 days, which is the month of January with an mean of $25.46 \%$ and $37.55 \%$ of the annual frost, the coldest month and month of November with 3.46 days and $5.33 \%$ of the lowest frozen point (Table 2). Desert location of Isfahan, the influx of Siberian cold tuber leaves from the northeast of the country to this area and smooth and cloudless nights are one of the main factors of Isfahan frosts. In any case, during the studied period, in April, in Isfahan, unlike Tabriz, no frozen is observed. Here it should be admitted that the duration of plant growth in Isfahan is more than Tabriz.

\section{Findings}

The hypothesis in relation to the calculated models is that the yield per hectare or the annual agricultural production can have a close relationship with the amount of investment or the cost spent on the same product. The hypothesis is presented in the form of a research:

$$
\begin{aligned}
& \mathrm{H}_{\circ}: \mathrm{B}_{i}=\circ \\
& \mathrm{H}_{1}: \mathrm{B}_{i} \neq \circ
\end{aligned}
$$




\section{$i=1,2,39 . . n$}

In the present research, the issue of "lack of difference" or "lack of communication" is the null hypothesis or falsehood. Therefore, the void hypothesis or null is "There is no difference in the yield of crop production in Isfahan and Tabriz". If the statistical tests show that the null hypothesis has not been accepted and rejected, the research hypothesis or successor will be accepted. This means that there is a difference in the yield of crops in Isfahan and Tabriz, depending on the variables involved. Regarding this issue, determination of independent variables and dependent variable of this research have been made based on the linear model $\mathrm{Y}=a+b x$ in the form of a multiple linear model. The dependent variable in this research is the yield or the amount of crop production. In order to broaden the attitude and conclusions of the analysis, four products of namely, arable wheat, dry farm wheat, arable barley and dry farm barley have been considered and evaluated.for carrying out the relevant tests. Before carrying out the tests to prove or reject the null hypothesis (0), the variables were defined as follows:

Temp temperature indicator (annual mean temperature to centigrade)

Precip rainfall (annual mean Precipitation per millimeter)

Frozen frost (number of freezing days per year)

Wheat1 Arable wheat (annual amount of arable wheat production per tonne)

CostW1 The cost of producing arable wheat (including all costs incurred in using inputs and total production costs in Rials)

Wheat2 Dry farm wheat (with the same conditions)

CostW2 The cost of producing Dry farm wheat (with the same conditions)

Barley1 Arable barley (with the same conditions)

CostB1 Arable barley Cost (with the same conditions)

Barley2 Dry farm barley (with the same conditions)

CostB2 The cost of producing dry farm barley (with the same conditions) 
The first step after determining and defining the data was to identify the dependent and independent variables. Accordingly, the dependent variable for performing the statistical tests, is the amount or yield of each of the four crops. so:

production rate or yield $x=$ (The effect of independent variables alone or collectively) $f$

In the above reiation, for example:

Wheat $=f($ Temp $)$ or Wheat $1=f($ Temp + Precip + Frozen $+\ldots)$

In these models, climate elements have had the most impact Therefore, the existence or absence of any kind of climatic factors in the amount of crop production is one of the basic assumptions of this research. In this study, it has been attempted to interfere in the models of the effects of other factors in the form of Rials cost, so that the parameters of " Autocorrelation " can not be created. The above model has been applied to all crops studied. In the first step, the proof of or rejection of the existence or difference between each variable is considered and is calculated in the form of linear regression model of a variable. In later stages, the amount of differences or correlations, or the effect of the sum of independent variables on the dependent variable in the form of a linear multiple model, has been calculated using inferential statistics of stepwise regression.

Tables 3,4,5 shows the descriptive statistics of the studied elements of Tabriz and Isfahan. Based on Table 3, the mean temperature of Isfahan during the studied period is more than 1.4 degree centigrade relative to Tabriz. In this period, the minimum temperature of Tabriz is 11.15 and its maximum is 14.14 degrees Celsius, while the same indicators for Isfahan are 15.38 and 17.96, respectively. During the study period, the range of temperature changes in Tabriz shows 2.99 centigrade, which is the same range for Isfahan 2.58. The temperature of Tabriz with a. skew of 0.16 is comparable to Isfahan with a relatively normal distribution of -2.5 .

Table 3. Descriptive statistics of temperature variables in Tabriz and Isfahan during the study period

\begin{tabular}{|l|c|c|c|c|c|}
\hline City & Mean & Min & Max & Range & skew \\
\hline Tabriz & & & & & \\
\hline Isfahan & 12.48 & 11.15 & 14.14 & 2.99 & 0.16 \\
\hline
\end{tabular}


Table 4. Descriptive statistics of Precipitation variables in Tabriz and Isfahan during the study period

\begin{tabular}{|l|c|c|c|c|c|}
\hline City & Mean & Min & Max & Range & skew \\
\hline Tabriz & & & & & 1.02 \\
\hline Isfahan & 245.24 & 148.6 & 384.1 & 235.5 & -4.6 \\
\hline
\end{tabular}

Table 5. Descriptive statistics of frozen variables in Tabriz and Isfahan during the study period

\begin{tabular}{|l|c|c|c|c|c|}
\hline City & Mean & Min & Max & Range & skew \\
\hline Tabriz & & & & & -7.2 \\
\hline Isfahan & 92.66 & 68 & 114 & 46 & 0.64 \\
\hline
\end{tabular}

\section{Correlation Analysis of Tabriz Data}

The main purpose of correlation analysis is to investigate the possibility of any correlation or relationship between variables and this analysis can determine some degree of mutual interactions between data (both independent and dependent variables). The most common method of correlation analysis is Pearson correlation, which is used in this research. The numbers in Table 6 (in the higher row) shown at the intersection of the data are related to the numerical value of the correlation (positive or negative), and the lower row numbers of the place of the $\mathrm{p}$ values or the probability of occurrence with The confidence range is $95 \%$. Moreover, the existence of such correlations can lead to misleading results due to the similarity of some functions and phenomena. Therefore, the existence of correlation between Precipitation and frozen (0.503) Which has an acceptable value of $p(0.56)$ is not much attention and is not considered in relation to the objectives of this research. However, the correlation between the production or yield of arable wheat and the total cost associated with it are related to the objectives of this research. Tables 6 and 7 show correlations and p values that are acceptable and significant for the purpose of this study:

Table 6. Significance correlations

\begin{tabular}{|c|c|c|c|c|c|c|c|}
\hline & $\begin{array}{c}\text { The cost } \\
\text { of arable } \\
\text { wheat }\end{array}$ & $\begin{array}{c}\text { The cost } \\
\text { of dry } \\
\text { farm } \\
\text { wheat }\end{array}$ & $\begin{array}{c}\text { The cost } \\
\text { of arable } \\
\text { barley }\end{array}$ & $\begin{array}{c}\text { The cost } \\
\text { of dry } \\
\text { farm } \\
\text { barley }\end{array}$ & $\begin{array}{c}\text { dry farm } \\
\text { barley } \\
\text { yield }\end{array}$ & $\begin{array}{l}\text { Total cost of } \\
\text { arable } \\
\text { wheat } \\
\text { production }\end{array}$ & $\begin{array}{c}\text { Total cost of } \\
\text { arable } \\
\text { barley } \\
\text { production }\end{array}$ \\
\hline frozen & 0.525 & 0.469 & 0.479 & 0.479 & & & \\
\hline Precipitation & & & & & 0.770 & & \\
\hline $\begin{array}{c}\text { arable wheat } \\
\text { yield }\end{array}$ & & & & & & 0.551 & \\
\hline $\begin{array}{c}\text { arable barley } \\
\text { yield }\end{array}$ & & & & & & & 0.542 \\
\hline
\end{tabular}


Regarding the correlations between variables, it is evident that:

1- By increasing the number or intensity of freezing days, the total costs of the crop production process are increased. The correlation is defined as an mean of about $50 \%$, which indicates an acceptable correlation.

2- There is a relatively high correlation between Precipitation and dry farm barley production (77\%), which is not true for other variables influenced by Precipitation (other crops).

3- The amount of arable wheat production is more than $55 \%$ correlated with the total cost of producing arable wheat.

4- The amount of arable barley production is more than $54 \%$ correlated with its total production costs.

\section{Correlation Analysis of Isfahan Data}

According to Table 7, which is based on Pearson correlation analysis, there are significace correlations between four variables dependent on the yield of arable wheat, dry farm wheat, arable barley and dry farm barley, and independent variables. The correlation coefficients tables 6 and 7 show correlations and significace $\mathrm{p}$ values in relation to the objectives of this study.

Table 7. Significance correlations

\begin{tabular}{|c|c|c|c|c|c|c|}
\hline & $\begin{array}{c}\text { The cost of } \\
\text { arable } \\
\text { wheat }\end{array}$ & $\begin{array}{c}\text { The cost of } \\
\text { dry farm } \\
\text { wheat }\end{array}$ & $\begin{array}{c}\text { The cost of } \\
\text { arable } \\
\text { barley }\end{array}$ & $\begin{array}{c}\text { The cost of } \\
\text { dry farm } \\
\text { barley }\end{array}$ & $\begin{array}{c}\text { dry farm } \\
\text { barley yield }\end{array}$ & $\begin{array}{c}\text { arable } \\
\text { barley yield }\end{array}$ \\
\hline $\begin{array}{c}\text { arable wheat } \\
\text { yield }\end{array}$ & -0.708 & -0.644 & 0.566 & -0.703 & & \\
\hline Dry wheat yield & & & & & 0.796 & \\
\hline Precipitation & & & & & & 0.559 \\
\hline
\end{tabular}

According to the table of correlations between variables, it is shown that:

1- There is a significace correlation with the strong correlation between the production of arable wheat and direct arable barley production (0.766).

2- There was a significace correlation between Precipitation and production of arable barley (0.559).

3. There is no significace correlation between frozen and other dependent variables.

4. There is an inverse correlation with strong intensity between the yield of arable wheat and its total production costs $(0.708)$. 


\section{Simple Regression Analysis of Tabriz Data}

In this research, simple regression, multiple, and stepwise regression models have been used. In the simple regression model the following results are obtained:

Regression analysis shows the effect of independent variables on the dependent variable and the extent of the changes resulting from it. In the first example, the effect of temperature changes on the production of arable wheat is calculated from the following equation:

$Y=\beta_{0}+\beta_{1} X+e$

In the above relation $\mathrm{Y}$ is the desired response or dependent variable, $\mathrm{X}$ is an independent or predictive variable, regression coefficients, and e is the error coefficient in conditions that have normal dispersion and has a mean of zero and its standard deviation is equivalent to sigma. The regression estimation for $B_{0}$ is calculated via $b_{0}, B_{1}$ through $b_{1}$ and the sigma is determined by $S$. As a result, the fitted equation will be as follows:

$\hat{Y}=b_{0}+b_{1} X$

Where $\hat{Y}$ is the fitted or predicted numerical value.

The calculation results for all variables can be analyzed as follows. The simple linear regression equation calculated for each variable has the following indices:

Estimation of sigma or estimated standard deviation around the regression line (root mean of standard error)

S

Coefficient of determination or correlation squared $\quad$ R-Sq

Adjusted coefficient for degrees of freedom $\quad$ R-Sq(adj)

If the variable is added to the equation, the R-Sq (even if the added variable does not have a real value) will increase.

In this study, analysis of variance, which is another part of the output of linear regression model, has been used. This analysis includes the sum of squares (SS) and SS regression with mean standard error (MS), and calculations related to F and P values. The degree of freedom is also shown with DF. In Tabriz, according to linear regression analysis of arable wheat models versus the cost of arable wheat 
production $(\mathrm{P}=0.033)$, arable barley versus arable barley production cost $(\mathrm{P}=0.037)$ with acceptable $\mathrm{P}$ value in the confidence range of $95 \%$ were significace and the rest of the models were rejected.

\section{Simple Regression Analysis of Isfahan Data}

Regarding the linear regression analysis of Isfahan data, yield models of barley wheat at the cost of production of arable wheat $(p=0.003)$ and arable barley versus precipitation $(p=0.030)$ with acceptable $\mathrm{p}$ values of $95 \%$ confidence interval and the rest of the models have been rejected.

\section{Multiple Regression Analysis of Tabriz Data}

As previously mentioned, in multiple regression analysis, instead of an independent variable, several independent variables are used to evaluate the effect of the sum of variables. The relevant model used in this study was as follows:

$Y=\beta_{0}+\beta_{1} X_{1}+\beta_{2} X_{2}+\cdots+\beta_{K} X_{K}+e$

As a result, the following equation is obtained for Tabriz:

wheat $_{1}=8227-325$ Temp $+4 / 96$ Pr ecip $-31 / 6$ Frozen $+0 / 000498$ Costw $_{1}$

The above linear equation is calculated for all variables in the model and only the relationship and the amount of impact Costw1 are acceptable and significace $(\mathrm{P}=0.077)$, and in the remaining cases, $\mathrm{P}$ value is more than $95 \%$ confidence level. As a result, it can be admitted that coefficients of cost variables and the amount of arable wheat production can not remain at zero by strong evidence and evidence. As a result, the prediction of the regression model is effective, while other variables do not show such a trend and have little effect on prediction.

\section{Multiple Regression Analysis of Isfahan data}

According to the model used in this study, which is mentioned in Tabriz, the following equation is obtained for Isfahan:

wheat $_{1}=10931-348$ Temp $+1 / 46$ Precip $-18 / 8$ Frozen $+0 / 000225$ Costiw $_{1}$ 
The above linear equation is calculated for all variables in the model and only the relationship and the amount of impact Costw1 are acceptable and significace $(P=0.013)$, In other cases, the value of $p$ is estimated to be higher than the confidence level. The corrected coefficient of $57.1 \%$ obtained for this equation is confirmed and significace. Therefore, in the case of Isfahan, multiple regression analysis provides an appropriate and significace estimation of the variables being computed and the extent of the effect of the factors and the resulting changes.

\section{Stepwise Regression Analysis of Tabriz Data}

It has been mentioned earlier that stepwise regression analysis with the aim of identifying useful and appropriate predictors adds or reduces variables in the regression model.

When choosing a stepwise regression analysis method, the predictor variables can be entered in the initial model. These variables are deleted if the value of $\mathrm{P}$ is greater than the value of the input alpha. If the goal of maintaining variables in the model irrespective of their $\mathrm{P}$ value, then it can be added $\alpha$ to the model. If the stepwise model is "forward" deletion, Value $\alpha$ adds to a new variable. If the stepwise model is in the state of " backward " deletion, its value $\boldsymbol{\alpha}_{\text {will be reduced to remove a new }}$ variable.

1- In stepwise regression analysis model, the production of arable wheat in comparison with temperature, Precipitation, frozen and total cost variables were only significace and validated with respect to $P$ values.

2- In stepwise regression analysis model, arable wheat production was significace only with Precipitation model.

3. In the stepwise regression analysis model for arable barley, only cost and Precipitation variables are significace.

4. In the stepwise regression analysis model for dry farm barley, only Precipitation model is significace.

\section{Stepwise regression analysis of Isfahan data}

1- In stepwise regression analysis, the amount of arable wheat production is significace with its production cost. 
2- In stepwise regression analysis model, dry farm wheat production is not significace with any of the variables.

3. In stepwise regression analysis, the production of arable barley with Precipitation is significace.

4. In stepwise regression analysis model, dry farm barley production is not significace with any of the variables.

\section{Conclusions and Suggestions}

1- In the event of climate change, better use of climate forecasts will be beneficial for increasing the profit of agricultural units.

2- Considering that many problems in the climate-agricultural basin are related to the economic assessment of climate and agricultural production, it is essential for agricultural areas to understand more about the relationship between climate elements and the rate of returns of each Agriculture unit, Before a comprehensive model of climate change is presented.

3- In the economic analysis of climate impacts, the collection of statistical information in a general and cumulative manner can not be effective Therefore, it is necessary to pay attention to the relationship and correlations between elements and climatic factors and agricultural units.

4-Seasonal weather forecasts, especially at the time of planting and harvest, can increase farmers' interest and profits, while reducing production risks.

5- Estimation and calculation of the practical relationship between net income of agricultural fields and climate variables can be effective in economic-agricultural development of geographical areas taking into account geographic and economic definitions by using statistical methods.

\section{Refrences}

Alton, P.; Djehiche, B.;and Stillberyer, D. 2000.On Modelling and Pricing Weather Derivatives.Energy and Power Risk Management:1:22.

Brookshire, D.S., Schulze,W.D.,Thayer, M.A., and Arge, R.C., 1982.Valuing Public Goods: A Comparison of Survey and Hedonic Approaches.American Economic Review. 72(1): 165-177.

Brown, A., Katz, W., and Murphy, H.1986.On The Economic Value of Seasonal-Precipitation Forecasts. Bulletin of American Meteorolgical Society 67.No7:833 - 841.

Environment Canada.2000.Climate Services Program. Climate Service Policy.Apr. 2000: 1-19. 
Harrison, D., and Rubinfeld, D.L., 1978. Hedonic Housing Prices and the Demand for Clean Air. Journal of Environmental Economics and Management 5:81-102.

Katz,W., and Murphy, H. 1982. Assessing the Value of Frost Fore -casts to Orchardists: A Dynamic Decision-Making Approach. Journal of Applied Meteorology 21: 518 - 531.

Kumar, K.S.Kavi, Parikh, j.2001. Indian Agriculture and Climate Sensitivity. Global Environmental Change 11:147-154.

Lixin, Zeng. 2000. Pricing Weather Derivatives .Journal of Risk Finance. Spring:72-78.

Maunder,W.J. 1970.The Value of the Weather. . London.

Mendelsohn,R., Dinar,A. 1999. Climate Change, Agriculture and Developing Countries: Does Adaptation Matter? The World Bank Research Observer. 14: 277- 293.

Rosen,S. 1974.Hedonic Prices and Implicit Market Product Differentiation in Pure Competition. Journal of Political Economy. No(2): 34- 55

Sanghi, A. 1997. The Climate Sensitivity of Brazilian Agriculture: Estimates from the Ricardian? The Impacts of Climate Change on Indian and Brazilian agriculture. World Bank, Washington. 